\title{
NARRATIVAS HIPERMIDIÁTICAS PARA INCLUSÃO EM AMBIENTE VIRTUAL DE ENSINO APRENDIZAGEM
}

\author{
FLORIANÓPOLIS/SC MAIO/2018
Silvia Regina Pochmann de Quevedo－ UFSC - silviareginaquevedo@hotmail.com Tarcísio Vanzin - UFSC - tvanzin@gmail.com
Luiz Antônio Moro Palazzo - UFSC - luiz.palazzo@gmail.com
Dóris Roncarelli - UFSC - dorisroncarelli@gmail.com \\ Tipo: Relato de Experiência Inovadora (EI) \\ Categoria: Conteúdos e Habilidades \\ Setor Educacional: EDUCAÇÃO MÉDIA E TECNOLÓGICA, EDUCAÇÃO SUPERIOR, \\ EDUCAÇÃO CONTINUADA EM GERAL
}

\begin{abstract}
RESUMO
Este trabalho trata do discurso narrativo sob diferentes linguagens com vistas à implementação de Ambientes Virtuais de Ensino Aprendizagem (AVEAs) capazes de oferecer suporte à inclusão. Como cada diferente público percebe uma narrativa? Em caso de pessoa com deficiência sensorial, existiria uma narrativa considerada ideal a este perfil? O objetivo deste trabalho foi investigar como se dão apropriações de diferentes narrativas em AVEA para o ensino de Geometria Descritiva, buscando atender alunos sem e com deficiência, neste estudo específico, surdez. Após a criação e implementação de diferentes gêneros de narrativas em hipermídia, os discursos foram apresentados aos potenciais estudantes para verificação de sua viabilidade no processo de ensino e aprendizagem. A experiência foi realizada com testagens junto a 26 alunos ao longo de quatro noites e posterior avaliação por meio de Grupos Focais. A comunicação entre os integrantes dos grupos foi estabelecida de diferentes modos, mediados pelo conhecimento dos códigos das línguas: alguns dos participantes dominavam a Língua Brasileira de Sinais (Libras), outros somente a Língua Portuguesa e outros detinham conhecimento de ambas. Houve a participação de duas intérpretes e moderadora em todos os encontros. A metodologia também envolveu a Análise Crítica do Discurso proposta pelo linguista inglês Norman Fairclough. Verificou-se que a narrativa hipermidiática construída com argumentação lógica sobrepôs-se em relação à ficção na preferência dos participantes da pesquisa e que a variedade de narrativas apresentadas em ambiente bilíngue favoreceu a interação entre os usuários e o processo de aprendizagem, estimulando a inclusão.
\end{abstract}

Palavras-chave: Ambiente Virtual de Aprendizagem, narrativas, inclusão, surdez 


\section{Introdução}

As narrativas sempre encantaram os seres humanos, mesmo antes da escrita, pela transmissão oral. Rodas ao redor do fogo, contos da meia-noite, todos os elementos e circunstâncias que fazem o homem transmitir o conhecimento e sonhar. Várias ciências a cotejam. A narrativa enquanto objeto de aprendizagem para este artigo é abordada na forma linguística. Isto é, tem começo, meio, fim, um clímax com o ápice da história e personagens que a vivem (BREMOND, 2008). Em tempos de novas tecnologias que permitem práticas incomuns de aprendizagem e que circulam hoje em Educação a Distância (EAD), aborda-se aqui uma intrigante pergunta: - Existiria um gênero ideal de narrativa à aprendizagem para diferentes públicos em Ambientes Virtuais de Ensino Aprendizagem (AVEAs)? A pergunta ganha contornos mais potentes se o AVEA exigir inclusão, tema caro à educação brasileira e pouco divulgado do ponto de vista político e social. Como levar a sala de aula inclusiva para o ambiente virtual em EAD?Com todas essas perguntas desenhando-se, um grupo de pesquisadores da Universidade XXXXXXXX, originários do Programa de Pós-Graduação XXXXXXXXX (CAPES nível 6), reuniu-se em torno do ambiente WebGD Acessível para o ensino de Geometria Descritiva a fim de encontrar respostas a essas indagações. As características únicas que envolvem a aprendizagem de quem possui deficiência sensorial (visão e cegueira) implicam cuidado com a Educação (CAMPBELL, 2009). Este artigo aborda a questão de trabalhar o AVEA do ponto de vista da deficiência auditiva/surdez a partir de conteúdo técnico exposto por meio de diferentes gêneros discursivos. Oferecer o mesmo conteúdo sob a forma de narrativas em hipermídia pode ser algo controverso na linguagem web, que não suporta redundância (SQUARISI, 2017). Mas para pessoas com deficiência auditiva sensorial isso faz diferença, pois, em Comunicação, a repetição de um tema amplia sua qualidade de apreensão e compreensão da mensagem.Segundo o último censo do IBGE o Brasil tem atualmente 9,7 milhões de pessoas com deficiência auditiva; destes 2,1 milhões apresentam deficiência auditiva severa, entre os quais 1 milhão são jovens de até 19 anos de idade (IBGE, 2018).As práticas incomuns de aprendizagem que se colocam com as novas tecnologias estão bastante vinculadas aos hábitos das novas gerações. A tecnologia revolucionou a vida do surdo, que se orienta a partir da visão e só domina fragmentos da Língua Portuguesa (QUADROS, 2018). Os Ambientes Virtuais de Ensino Aprendizagem bilíngues e inclusivos podem derrubar barreiras.

\section{Método}

A experimentação envolveu manancial teórico capaz de fundamentar a prática. Foram realizadas três Revisões Sistemáticas de Literatura junto a plataformas de viés interdisciplinar: Scopus, Web of Knowledge e Scielo com vistas à inclusão e à surdez 
nos moldes propostos pela Cochrane Collaboration (2018), quando se procurou identificar como o público alvo - alunos sem deficiência, com deficiência auditiva e surdos - poderia aprender Geometria Descritiva em Ambiente Virtual. A pesquisa de revisão incluiu artigos publicados em periódicos, bases de dados em vídeo (Youtube), do Instituto Nacional de Educação de Surdos (INES) e da Federação Nacional de Educação e Integração dos Surdos (FENEIS) devido à representatividade dessas instituições em nível nacional. As buscas resultaram na elaboração de quadros e mapas mentais com uma primeira síntese das pesquisas, delimitando-se datas, pesquisadores, público alvo, propostas e resultados obtidos. Concomitante a esse procedimento houve a implementação em AVEA das narrativas em três gêneros: História em Quadrinhos (N1), Contos (N2) e Narrativa Dissertativa (N3), esta no estilo de textos científicos (QUEVEDO, 2013). O próximo passo foi realizar Grupos Focais junto a 26 alunos com e sem deficiência auditiva/surdez, em quatro sessões subsequentes, quando se pretendeu simular a sala de aula virtual inclusiva. Os alunos se conheciam da sala de aula presencial, com exceção de dois ouvintes convidados para o último dia. A cada noite houve a presença de duas intérpretes Libras (Língua Brasileira de Sinais) e uma moderadora. As narrativas foram testadas isoladamente e depois todas ao mesmo tempo em uma única sessão. Os participantes não repetiram sua experiência, isto é, quem integrou o G1 (Grupo1) não participou dos demais e assim sucessivamente até o último dia, quando o G4 foi formado para o teste geral do Ambiente Virtual.Os encontros foram gravados em vídeo com três câmeras (para o grupo, apenas para os alunos surdos, para as intérpretes) e posteriormente decupados, com a aplicação da Análise Crítica do Discurso proposta pelo linguista inglês Norman Fairclough (2001). Também se acrescentou à metodologia a realização de entrevistas em profundidade junto a especialistas. Um computador com acesso a banda larga foi disponibilizado para cada participante, que acessou a narrativa e realizou atividades de aprendizagem ao final da leitura. Todas as narrativas eram bilíngues: Língua Portuguesa escrita e oral, Libras em vídeo. A HQ foi oferecida apenas em português, mas com exercícios propostos também em Libras. A N2 (Contos) incluía um conto principal e outros três mini-contos, interconectados. As narrativas continham características de hipermídia: hiperlinks com informações técnicas, caminhos alternativos ao veio principal de cada história e diferentes finais, caracterizando a metáfora do labirinto (LEÃO, 2005) no qual o usuário tem acesso a várias linguagens, porém com risco de se perder em fronteiras indefinidas. O sistema foi projetado para permitir a comunicação entre os participantes por chat e com identificação de erro na atividade (Imagem 1). 


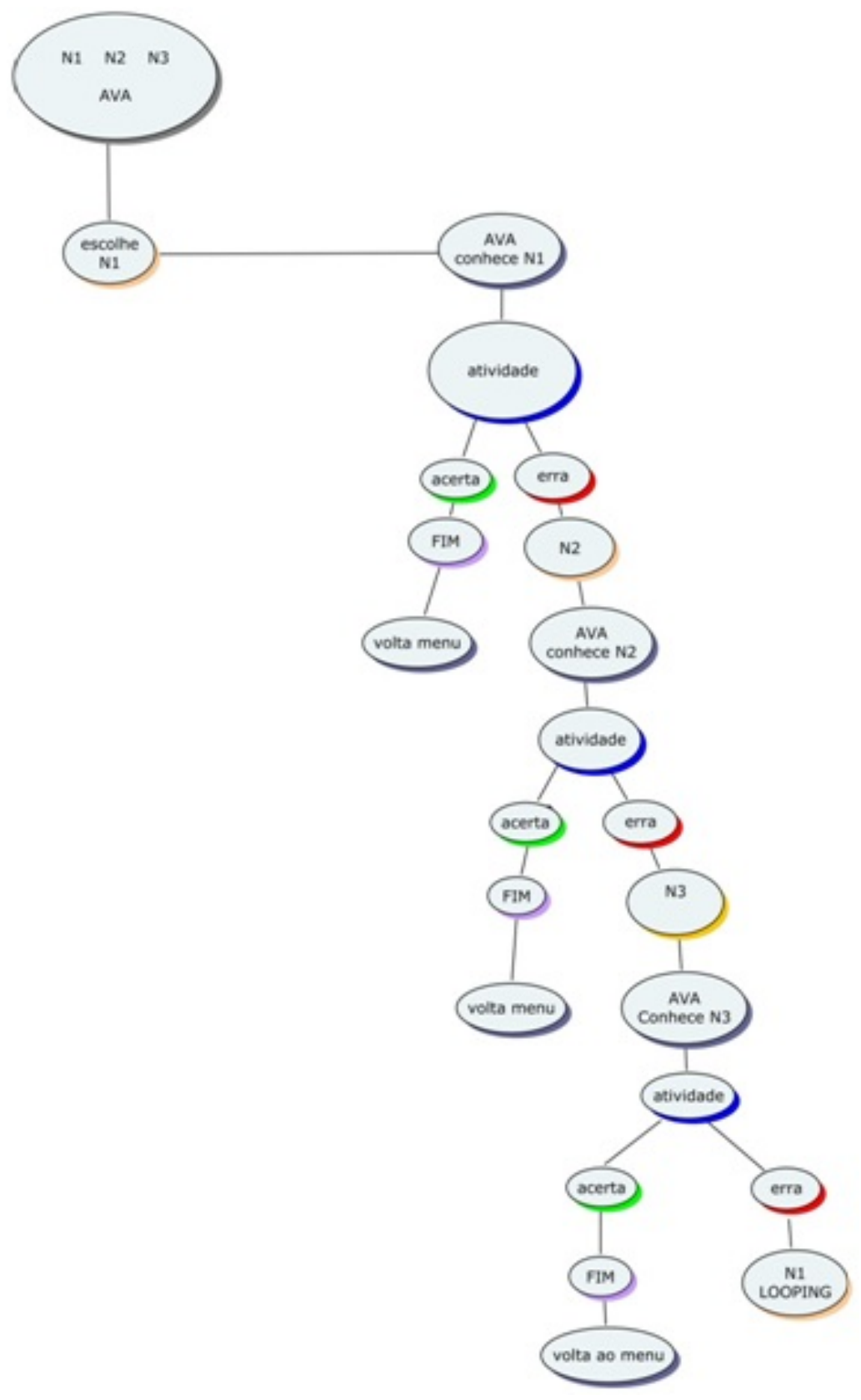

Imagem 1: Mapa de navegação demonstra o funcionamento do ambiente virtual com narrativas

A Imagem 1 demonstra o percurso do usuário no sistema. Caso incorresse em erro, automaticamente era transferido para outra narrativa, até conhecer, se necessário, todas elas e então, no "looping" chegar ao tutor/professor para dirimir suas dúvidas. Seguiu-se aos testes a realização de Grupos Focais, onde tudo foi observado. A disposição do círculo teve que ser previamente planejada, pois as intérpretes precisavam trabalhar lado a lado e de frente aos alunos surdos para melhor desempenho, pois assim poderiam se apoiar mutuamente no processo de tradução. A Imagem 2 mostra o Grupo Focal realizado para os testes da $\mathrm{HQ}$. 


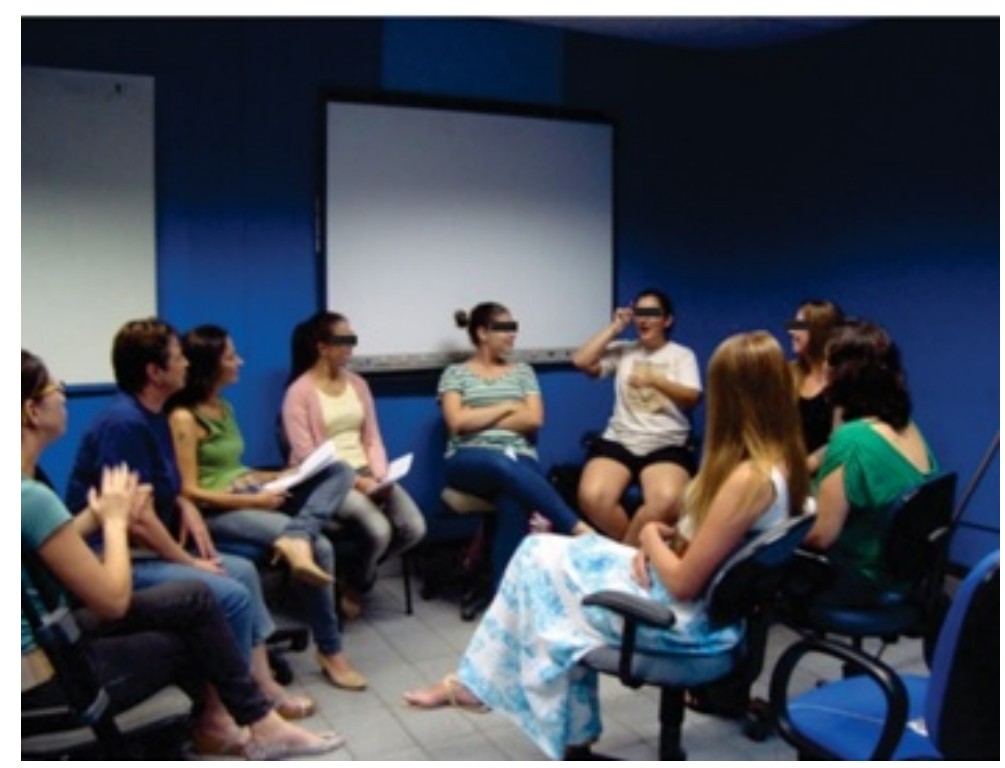

Imagem 2: Grupo Focal para analisar a $\mathrm{HQ}$ em ambiente virtual

A análise gramatical baseada na Análise Crítica do Discurso (ACD) de Norman Fairclough buscou aferir se os enunciados dos participantes continham sentenças positivas ou negativas com relação às narrativas. Para tanto se partiu do conceito de proposição na concepção de Wittgenstein (2001), em que o conhecimento precisa ser proposicionado ou seja, expresso por meio do pensamento que é colocado ao mundo através de uma proposição, uma sentença declarativa com um valor de verdade e um sentido.

\section{Resultados}

Cada turno de fala entre os alunos foi considerado um enunciado, o que permitiu verificar que nas discussões dos Grupos Focais, ao contrário do que se esperava menor exposição do aluno surdo (em virtude de sua língua ser gestual) - isso não aconteceu. Ao contrário, em duas das quatro sessões realizadas os alunos surdos manifestaram-se com muito mais frequência do que os ouvintes. Na opinião das participantes, o excesso de hiperlinks nas narrativas causou confusão e atrapalhou a navegação no sistema, comprometendo seu desempenho no uso do sistema. Para os participantes da pesquisa, o problema da confusão citada não se localiza na narrativa em hipermídia com vários finais, começos e hiperlinks se a navegação e a internet funcionarem. "Quanto mais finais melhor, se tiver a ver com a história, aproveita a mesma história para ensinar coisas diferentes. [...] Acho que assim como um objeto, a história deveria ser posta num triedro, para fazer três projeções, com três finais diferentes", sugeriu o aluno ouvinte Cássio[1]. O tamanho dos textos a serem lidos, especialmente nos contos, causou apreensão, porque eles foram considerados "muito 
longos". Isso determinou outro questionamento - e verdadeiro desafio - ao conteudistas, pois uma página e meia em Word do conto principal, por exemplo, ocasionou 35 páginas do um livro virtual implementado. Os participantes surdos e ouvintes sugeriram que a "numeração" de páginas dos contos não deveria ser feita não através de números, como se apresentava, mas por meio de palavras-chaves com o tema de interesse de cada um, o que talvez gerasse a elaboração de um glossário com as palavras de difícil tradução. Na concepção dos participantes da experiência, a narrativa mais confortável para conhecer o conteúdo e estudar foi a Narrativa Dissertativa (N3) e a menos confortável Contos (N2). Entre os que escolheram a Narrativa Dissertativa como mais confortável houve unanimidade: todos preferiram a Dissertativa, afirmando ter sido esta a forma como melhor entenderam o conteúdo, indo "direto ao ponto". Os contos foram considerados "cansativos". O verbo entender, na análise gramatical, surgiu na fala de alunos pertencentes aos dois públicos. Contudo, a Narrativa Dissertativa não obteve unanimidade. Para alunos ouvintes participantes da última sessão, o caráter literário dos contos tornou a leitura "mais agradável" e uma forma "mais confortável" e "criativa" de aprender conteúdos técnicos. No dia anterior, um aluno surdo havia elegido a $\mathrm{HQ}$ como melhor narrativa para estudar devido ao que mencionou como "caráter pedagógico" de brincar no aprendizado. Após a transcrição, leitura e análise do conteúdo das quatro noites de Grupos Focais e da Análise Crítica do Discurso realizada por meio das proposições dos 26 alunos, chegou-se à elaboração de 31 recomendações apresentadas na Imagem 3.

\begin{tabular}{|c|c|c|c|}
\hline Conteúdo & Design & Navegação & Contribuição Pedagógica \\
\hline $\begin{array}{l}\text { Vincular conceito técnico à } \\
\text { narrativa por meio de } \\
\text { hiperlinks demarcados }\end{array}$ & $\begin{array}{l}\text { Padrẫo único de linguagem visual } \\
\text { (especialmente para links) }\end{array}$ & $\begin{array}{l}\text { Fácil acesso: leitura } \\
\text { linear ou caminhos } \\
\text { alternativos, ou por } \\
\text { meio de hiperlinks. }\end{array}$ & $\begin{array}{l}\text { Deve ser oferecida a } \\
\text { 'resposta esperada' a } \\
\text { tarefas. Os alunos querem } \\
\text { saber onde erraram, para } \\
\text { repetir o exercício e não } \\
\text { errar mais. }\end{array}$ \\
\hline $\begin{array}{l}\text { Pluralidade de géneros } \\
\text { reforça aprendizagem }\end{array}$ & $\begin{array}{l}\text { Destaque para botôes de controle no } \\
\text { vídeo Libras a fim de não tirar a } \\
\text { atenção de leitura do ouvinte }\end{array}$ & $\begin{array}{l}\text { Hiperlinks nåo devem } \\
\text { interferir no enredo, } \\
\text { mas conter conexões } \\
\text { com o veio principal } \\
\text { da história }\end{array}$ & $\begin{array}{l}\text { Respostas a exercícios de } \\
\text { "completar" devem ser } \\
\text { oferecidas em vídeo Libras } \\
\text { para alunos surdos }\end{array}$ \\
\hline $\begin{array}{l}\text { Deve contemplar diferentes } \\
\text { formas de navegação } \\
\text { (linear ou não) }\end{array}$ & $\begin{array}{l}\text { A preferência de apresentação da } \\
\text { HQ recai no formato "tirinhas" }\end{array}$ & $\begin{array}{l}\text { A volta de um } \\
\text { hiperlink deve } \\
\text { remeter ao ponto de } \\
\text { leitura em que se } \\
\text { estava }\end{array}$ & $\begin{array}{l}\text { Atividades devem ser } \\
\text { oferecidas jodependente. } \\
\text { das narrativas, como } \\
\text { "Bolsa de atividades" }\end{array}$ \\
\hline $\begin{array}{l}\text { Textos precisam de } \\
\text { independência (devem } \\
\text { estar interconectados, mas } \\
\text { permitir entendimento } \\
\text { isolado do enredo) }\end{array}$ & $\begin{array}{l}\text { Cuidado na edição de vídeos, cortes } \\
\text { causam desconforto e comprometem } \\
\text { compreensãa }\end{array}$ & $\begin{array}{l}\text { Aumentar a Libras e } \\
\text { diminuir o texto em } \\
\text { português e vice- } \\
\text { versa evita 'ruídos' }\end{array}$ & $\begin{array}{l}\text { Estudo daLibras como } \\
\text { parte integrante do } \\
\text { currículo para ouvintes } \\
\text { aumenta poder da inclusão }\end{array}$ \\
\hline Exige Libras & $\begin{array}{l}\text { Chat deve aparecer com énfase para } \\
\text { compartilhamento }\end{array}$ & & $\begin{array}{l}\text { Elaborar histórias com } \\
\text { base em valores culturais } \\
\text { e emocionais }\end{array}$ \\
\hline
\end{tabular}




\begin{tabular}{|c|c|c|c|}
\hline $\begin{array}{l}\text { Conceitos complexos } \\
\text { devem associar imagens a } \\
\text { palavras ou legendas }\end{array}$ & $\begin{array}{l}\text { Chat em sala bilíngue deve ser por } \\
\text { webcam }\end{array}$ & & \\
\hline $\begin{array}{l}\text { Intérprete deve } \text { "olhar }^{8} \text { para } \\
\text { as legendas no vídeo ao } \\
\text { sinalizar }\end{array}$ & $\begin{array}{l}\text { Numeração muito extensa leva à } \\
\text { sensação de que "há muito para ser } \\
\text { lido }{ }^{*}\end{array}$ & & \\
\hline $\begin{array}{l}\text { Muitos finais para } \\
\text { contemplar o conteúdo } \\
\text { técnico com a mesma } \\
\text { história }\end{array}$ & $\begin{array}{l}\text { Numeração de páginas por meio de } \\
\text { palavras associadas ou imagens } \\
\text { associadas ao conteúdo }\end{array}$ & & \\
\hline \multirow[t]{6}{*}{ Intérprete também para HQ } & $\begin{array}{l}\text { Glossário em Libras e portuguếs } \\
\text { para o aluno surdo }\end{array}$ & & \\
\hline & $\begin{array}{l}\text { Hiperlink para o surdo deve abrir } \\
\text { tanto na legenda abaixo do vídeo do } \\
\text { intérprete quanto no próprio corpo do } \\
\text { texto em português }\end{array}$ & & \\
\hline & $\begin{array}{l}\text { A cor para o surdo sempre indica } \\
\text { mudança de contexto }\end{array}$ & & \\
\hline & $\begin{array}{l}\text { Fotos animadas contêm forte valor } \\
\text { de atração }\end{array}$ & & \\
\hline & $\begin{array}{l}\text { Um índice com a apresentação do } \\
\text { conteúdo a ser estudado é } \\
\text { fundamental para que o aluno se } \\
\text { situe em relação ao que será } \\
\text { estudado e as opções que tem de } \\
\text { aprender aquele conteúdo }\end{array}$ & & \\
\hline & $\begin{array}{l}\text { Todas as formas de arte devem ser } \\
\text { utilizadas na web como meio de } \\
\text { potencializar valor de atração e } \\
\text { atenção a alunos surdos e ouvintes. } \\
\text { Alunos surdos também apreciam } \\
\text { "ver"música }\end{array}$ & & \\
\hline
\end{tabular}

Imagem 3: Recomendações em narrativas para AVEAs Inclusivos

Os alunos participantes da pesquisa disseram apreciar o fato de a Narrativa Dissertativa, mesmo com finais e caminhos alternativos de leitura, demonstrar um texto alicerçado na argumentação, sem as referências a outras histórias e fantasias, porque "na hora de aprender" a "ordenação e a sistematização das informações é muito importante". Nesse caso, será preciso considerar a peculiaridade de quem gosta de aprender fora da argumentação lógica. Há narrativas para todos os gostos. E elas é que podem demarcar diferenças, não a "deficiência" de um aluno ou aluna. Kemczinsky (2018) já detectou a importância do detalhamento de contextos e a personalização de sistemas de acordo com diferentes ontologias, capazes de modelar o contexto do aluno em diversos cenários, adaptando conteúdo, navegação e apresentação dos ambientes de aprendizagem. Embora sensibilidade e ciência ainda não sejam um conceito amadurecido em sistemas de educação a distância, começam a surgir novos pontos de vista para a composição desses ambientes, baseados em uma consciência cultural afinada ao contexto dos alunos histórico, social e emocional dos alunos (KEMCZINSKY, 2018). Para alunos surdos e ouvintes, e especialmente para aqueles que se entendem por meio do uso de Português e Libras, ambientes bilíngues têm grandes chances de serem bem acolhidos e - mais importante: vivenciados. Sensibilidade e ciência podem compor ambientes virtuais de aprendizagem que não se limitem a "copiar" sistemas tradicionais de ensino (MORAN, 2017), que possibilitem um olhar a novos paradigmas cada vez mais presentes e motivadores de pessoas atentas a questões sociais e 
ambientais.

\section{Considerações Finais}

Na perspectiva adotada para este trabalho conclui-se que a aprendizagem em AVEA por meio de diferentes gêneros de narrativas se dá para todos os alunos, com ou sem deficiência, independente de seu perfil e atendendo às diferentes formas que o aluno gosta de aprender, para que aprenda mais e melhor. A pesquisa indicou que a preferência de ambos, surdos e ouvintes, recaiu sobre a Narrativa Dissertativa, considerada como a melhor para aprender devido a seu aspecto argumentativo, de fundamento lógico, longe da ficção. A pesquisa também pontuou a importância do uso de diferentes narrativas para que o acolhimento pelo sistema virtual não se dê pela definição da deficiência do aluno, mas por seu desejo em primeiro lugar. Basta ao aluno escolher entre os gêneros, ou visitar todos. Em AVEA Inclusivo a pergunta é: "Com qual narrativa você mais gosta de estudar?" A pesquisa demonstrou que Ambientes bilíngues entre surdos conhecedores de português e ouvintes que sabem Libras diluem a correlação de forças do ambiente, tornando-o mais homogêneo. Os alunos surdos inclusive, em duas das quatro sessões realizadas, proposicionaram mais do que os alunos ouvintes. Levado ao virtual, esse contexto pode ser ainda mais diluído, pois a oferta do conteúdo em duas línguas propicia condições de compartilhamento em tempo real. A testagem de diferentes narrativas demonstrou que se torna fundamental a necessária pluralidade de abordagens e o reconhecimento das visões de áreas disciplinares que atuam no projeto do AVEA, alinhavadas pelo fio da interdisciplinaridade. Do ponto de vista tecnológico, os sistemas podem avançar com o desenvolvimento de excelentes formas de conexão e navegação, ancorados nas diferenças dos alunos não no desenho universal que atende à massa homogênea, mas, antes, a singularidade do sujeito. O sistema será mais eficaz e eficiente se moldar-se aos mapas mentais dos perfis requeridos, oferecendo explosão de linguagens web, explorando todas as possibilidades, sem causar ruídos entre os públicos. Essas características poderiam ser 'móveis', flutuantes na tela, com maior ou menor incidência de uma e outra. Se o vídeo com gestos confunde o aluno ouvinte, porque não um botão para minimizá-lo? Se um aluno gosta do reino da fantasia, porque não uma história com personagens e fotos animadas para animá-lo? É a singularidade. Bilinguismo significa o encontro de duas línguas. É ótimo que as crianças surdas estejam em sala de aula com as ouvintes. Será excelente se, junto a isso, conversarem entre si sem ajuda de intérprete. Os Ambientes Virtuais de Ensino Aprendizagem (AVEAs) inclusivos apresentam potencial para esse avanço: permitem não colocar diferenças no momento de estudar e aprender com diferentes narrativas. 


\section{Referências Bibliográficas}

BRASIL. Instituto Brasileiro de Geografia e Estatística (IBGE). Censo 2010. Disponível em https://censo2010.ibge.gov.br/ Acesso em abril 2018.

BREMOND, C.et al A lógica dos possíveis narrativos. In: BARTHES, Roland et al. Análise estrutural da narrativa. Petrópolis: Editora Vozes, 2008.

COCHRANE COLLABORATION. Disponível em http://www.cochrane.org/ Acesso em março 2018.

FAIRCLOUGH, N. Discurso e mudança social. Coord. trad.rev. técnica e pref. I. Magalhães. Brasília: Editora Universidade de Brasília, 2001.

KENCZINSKY, A. Método de Avaliação para Ambientes E-learning Tese (doutorado, 2005) - Universidade Federal de Santa Catarina, Centro Tecnológico. Programa de PósGraduação em Engenharia de Produção. Disponível em https://repositorio.ufsc.br/bitstream/handle/123456789/101724/224282.pdf?sequence =1 \&isAllowed=y Acesso em abril 2018.

LEÃO, L.O labirinto da hipermídia: arquitetura e navegação no ciberespaço. São Paulo: Editora lluminuras, 2005.

MORAN, J. M. (2007) Avaliação do Ensino Superior a Distância no Brasil. Disponível em www.eca.usp.br/prof/moran. Acesso em dezembro 2017.

QUADROS, R.M. (2006) O contexto escolar do aluno surdo e o papel das línguas. Disponível em www.sj.ifsc.edu.br/ nepes/docs/midiateca_artigos/escrita.../texto65.doc. Acesso em março 2018.

QUEVEDO, S.R.P. de Narrativas Hipermiáticas para Ambientes Virtuais Inclusivos Tese (Doutorado) Universidade Federal de Santa Catarina. Programa de Pós-Graduação em Engenharia e Gestão do Conhecimento, Florianópolis: 2013.

SQUARISI,

D. Sempre

um

papo.

Disponível em http://www2.camara.leg.br/camaranoticias/tv/materias/SEMPRE-UM-PAPO/183248-DADSQUARISI-E-MARCIO-COTRIM-\%28JORNALISTAS\%29-\%28BL.1\%29.html. Acesso em dezembro 2017. 
[1] Nome fictício para preserver a fonte 